\title{
Cystinuria: Defective Intestinal Transport of Dibasic Amino Acids and Cystine*
}

\author{
S. O. Thier, $\nmid$ S. Segal, M. Fox, $\$$ A. Blair, and L. E. Rosenberg $§$ \\ (From the Clinical Endocrinology Branch and the Metabolic Diseases Branch, National In- \\ stitute of Arthritis and Metabolic Diseases, and the Metabolism Service, \\ National Cancer Institute, Bethesda, Md.)
}

The clinical manifestations of cystinuria are localized to the urinary tract and result from the formation of cystine calculi. The findings of increased excretion of cystine, lysine, arginine, and ornithine in the urine at a time when the plasma levels of these amino acids were normal or low suggested to Dent and Rose (2) that a renal tubular reabsorptive site, shared by the involved amino acids, was defective. Investigations from our laboratory (3), using slices of human kidney, failed to confirm the hypothesis of Dent and Rose. Cystine did not compete with the dibasic amino acids in vitro, and although the transport of lysine and arginine was defective in cystinuria, cystine transport was unimpaired.

Although evidence had been accumulating for over 60 years (4-6), it was not until 1960 that the concept of an intestinal transport defect in cystinuria emerged. Milne, Asatoor, and coworkers $(7,8)$ noted that urinary and fecal excretion of the diamines, cadaverine and putrescine, was elevated in cystinuric subjects fed lysine and ornithine, respectively. These diamines are formed by bacterial decarboxylation of the dibasic amino acids. Hence, it was postulated that lysine and ornithine were poorly absorbed from the small intestine in cystinuria and were presented to colonic bacteria in increased amounts, resulting in excessive diamine formation and excretion. These authors provided further evidence for de-

* Submitted for publication August 31, 1964 ; accepted November 27, 1964.

A portion of this work was reported in a preliminary communication (1).

$\dagger$ Present address: Massachusetts General Hospital, Boston, Mass.

$\ddagger$ Present address: Palo Alto Clinic, Palo Alto, Calif. $\S$ Address requests for reprints to: Dr. L. E. Rosenberg, Metabolism Service, National Cancer Institute, Bethesda, Md. 20014. fective gut absorption by showing that oral ingestion of arginine in cystinurics was followed by minimal elevations of plasma arginine compared to results obtained with control subjects. We have previously reported a defect in the uptake of lysine and cystine by jejunal mucosa from cystinuric subjects (1), an observation made simultaneously by McCarthy and his associates (9).

The present studies extend our previous observations and show that lysine and cystine are accumulated by saturable, energy-dependent processes in the human jejunum and that these two amino acids are mutually inhibitory in the gut. Furthermore, it is shown that some patients with cystinuria do not share the intestinal transport defect for cystine and lysine.

\section{Methods}

After an overnight fast, peroral biopsy of the intestinal mucosa was performed with a Rubin tube placed at the ligament of Treitz under fluoroscopic control. A total of 75 biopsies was performed on 18 normal volunteers and 12 patients with cystinuria. The 14 male and four female volunteers were between the ages of 18 and 36 years; the seven female and five male patients were between the ages of 19 and 48. All patients with cystinuria had elevated concentrations of cystine, lysine, arginine, and ornithine in the urine, and all had formed several urinary calculi composed of cystine.

The biopsy specimens weighing between 1 and $7 \mathrm{mg}$ were placed in chilled, amino-acid free Krebs-Ringer bicarbonate buffer 5 to 10 minutes before incubation. The tissue was then transferred to 25-ml Erlenmeyer flasks containing $2.0 \mathrm{ml}$ of Krebs-Ringer bicarbonate buffer $(\mathrm{pH} \mathrm{7.4)}$ and labeled amino acid. After aerobic $\left(\begin{array}{llllll}95 \% & \mathrm{O}_{2}-5 \% & \mathrm{CO}_{2}\end{array}\right)$ or anaerobic $\left(\begin{array}{llll}95 \% & \mathrm{~N}_{2}-5 \% & \mathrm{CO}_{2}\end{array}\right)$ incubation for 15 to 120 minutes at $37^{\circ} \mathrm{C}$ in a Dubnoff metabolic shaker, tissues were rinsed in saline, blotted, weighed, and placed in distilled water. The free amino acid content of the tissue was equilibrated with $1.0 \mathrm{ml}$ of distilled water by boiling for 6 minutes. Two-tenths$\mathrm{ml}$ samples of aqueous tissue supernatant and remaining media were counted in a liquid scintillation spectrometer 
TABLE I

Distribution ratios for glycine, L-lysine, and L-cystine under control and anaerobic conditions and for glycine in the presence of 2,4-dinitrophenol (DNP) $\left(10^{-5} \mathrm{M}\right)^{*}$

\begin{tabular}{clcc}
\hline Amino acid & $\begin{array}{c}\text { Experimental } \\
\text { conditions }\end{array}$ & $\begin{array}{c}\text { Distribution ratio } \\
\pm \text { SD }\end{array}$ & p value† \\
\hline Glycine $(0.03 \mathrm{mM})$ & Control & $4.70 \pm 1.12$ & $<0.001$ \\
& Anaerobiosis & $1.48 \pm 0.19$ & $<0.001$ \\
& DNP & $1.53 \pm 0.18$ & $<0.001$ \\
L-Lysine $(0.22 \mathrm{mM})$ & Control & $4.45 \pm 0.62$ & $<0.001$
\end{tabular}

* The incubation times were 45 minutes for glycine, 30 minutes for L-cystine, and 15 minutes for L-lysine. For studies under anaerobic conditions the Krebs-Ringer bicarbonate buffer was gassed with $95 \% \mathrm{~N}_{2}-5 \% \mathrm{CO}_{2}$. The incubation flasks were regassed with the $\mathrm{N}_{2}-\mathrm{CO}_{2}$ and stoppered for the duration of the experiment.

$\dagger$ Distribution ratios under anaerobic conditions and in the presence of 2,4-DNP were significantly different from control values as determined by Student's $t$ test.

with an efficiency of $57 \%$ for $C^{14}$. Samples of the aqueous tissue extracts were chromatographed with a one-dimensional paper system in butanol-acetic acidwater $(4: 1: 2)$, and in all cases over $90 \%$ of the radioactivity was recovered at the appropriate $R_{f}$ for the amino acid originally added to the medium. Total tissue water was determined to be the difference in weight before and after drying in a crucible for 24 hours at $105^{\circ} \mathrm{C}$ in a vacuum oven. Extracellular fluid space (ECF) was defined as the space of distribution of $\mathrm{C}^{\mathbf{1 4}}$ inulin. Distribution ratios defined as $\mathrm{cpm} / \mathrm{ml}$ intracellular fluid $(\mathrm{ICF}) / \mathrm{cpm} / \mathrm{ml}$ medium were calculated using the formula:

$\mathrm{cpm} / \mathrm{ml} \mathrm{ICF}$

$=$ net tissue $\mathrm{cpm}-[(\mathrm{cpm} / \mathrm{ml}$ medium $) \times($ inulin space $)]$ $\mathrm{ml}$ tissue water $-\mathrm{ml}$ inulin space.

Distribution ratios were measured under steady-state conditions when feasible. A steady state exists when the rate of amino acid movement into the cell (influx) equals the rate of exit from the cell (efflux).

Analyses of the kinetics of the saturable component of biological transport (10) were carried out in the manner described by Akedo and Christensen (11). In the present study a correction was made for the portion of transport that was nonenergy dependent and presumably nonsaturable by subtracting from the total intracellular accumulation of amino acid the value for the accumulation under anaerobic conditions during the same period of incubation. This correction is analogous to the one used by Krane and Crane (12) except that energy production was blocked anaerobically rather than chemically. Alternatively, diffusion was corrected for by subtracting unity from the observed distribution ratios, and it was found that results with this method did not change significantly the derived values.

L-Cystine- $\mathrm{S}^{35}$ (.069 mc per $\left.\mathrm{mg}\right){ }^{1}$ L-lysine-U-C ${ }^{14}(1.0$ $\mathrm{mc}$ per $\mathrm{mg}),{ }^{2}$ L-arginine-U-C ${ }^{14}$ (1.4 $\mathrm{mc}$ per $\left.\mathrm{mg}\right){ }^{2}$

1 Schwartz Bioresearch, Mt. Vernon, N. Y.

2 New England Nuclear Corp., Boston, Mass. glycine-2- $\mathrm{C}^{14}(0.04 \mathrm{mc}$ per $\mathrm{mg}),^{2}$ and inulin-carboxyl$\mathrm{C}^{14}$, mol wt, 3,000 to 4,000 ( $2.1 \mathrm{mc}$ per $\left.\mathrm{mg}\right)$, $^{2}$ were obtained commercially, as were all unlabeled amino acids ${ }^{3}$ and 2,4-dinitrophenol.4

For studies in which $2.4 \mathrm{mM}$ concentrations of cystine

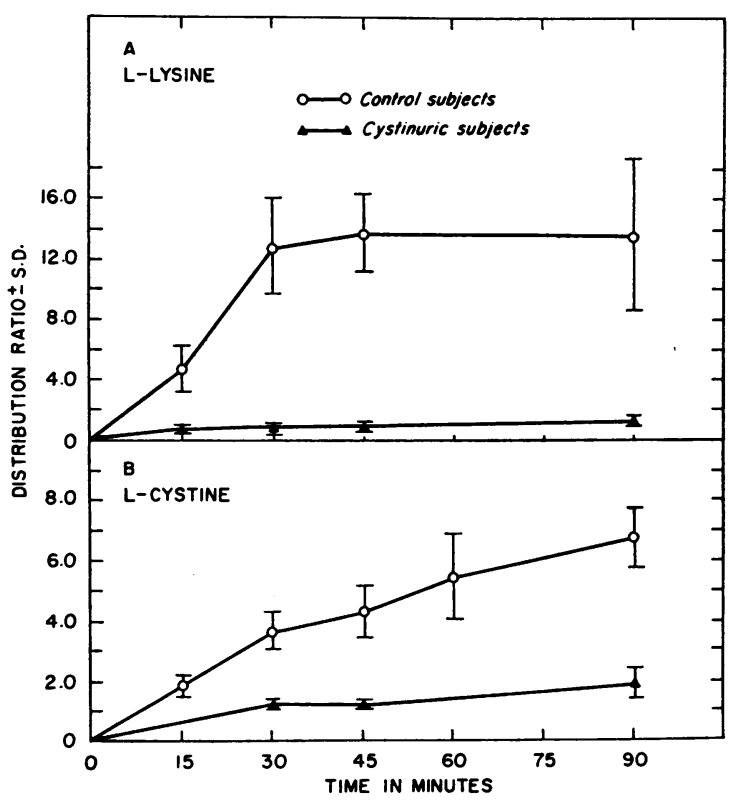

Fig. 1. UPtAKe OF L-LYSINE-C ${ }^{14}$ AND L-CYSTINE-S 35 IN INTESTINAL MUCOSA FROM NORMAL AND CYSTINURIC HUMAN SUBJECTS. The distribution ratios for lysine $(0.065 \mathrm{mM})$ and cystine $(0.03 \mathrm{mM})$ are plotted as a function of time of incubation. The control points represent the average of determination in four or more subjects. The points for the cystinuric subjects represent the average of determinations in three patients for lysine and two patients for cystine.

\footnotetext{
3 Nutritional Biochemicals Corp., Cleveland, Ohio.

4 Eastman Organic Chemicals, Rochester, N. Y.
} 

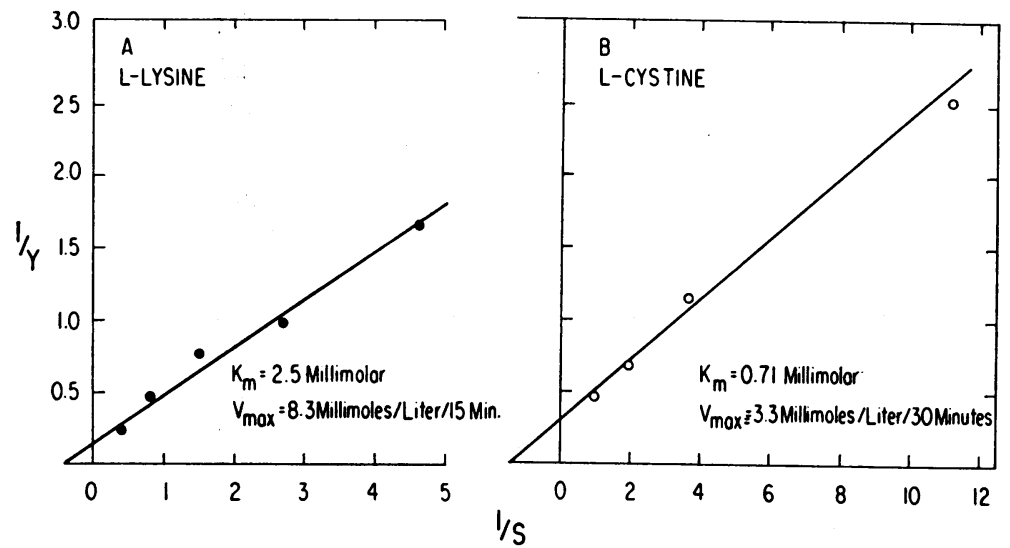

Fig. 2. Lineweaver-Burk analysis of Cystine AND LySine transport IN NORMAL HUMAN INTESTINE. The rate of accumulation of amino acid in millimoles per liter per unit time $(\mathrm{Y})$ as a function of substrate concentration in millimoles per liter $(\mathrm{S})$ is presented using the double reciprocal plot of Lineweaver and Burk. $\mathrm{V}_{\max }=$ maximal transport rate; $\mathrm{Km}=$ apparent affinity constant for transport. Each point represents the average of three or more determinations.

were used to inhibit the uptake of lysine, small quantities of $0.08 \mathrm{~N}$ sodium hydroxide were used to dissolve the cystine, and a comparable amount of sodium hydroxide was added to the control flasks.

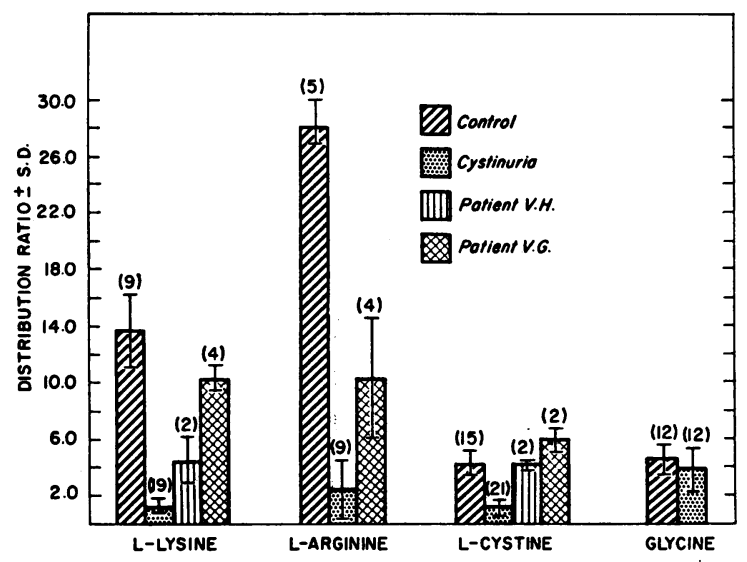

Fig. 3. Defective intestinal transport of lysine, ARgININE, AND CYSTINE IN CYSTINURIC SUBJECTS. The distribution ratios in control and cystinuric subjects for lysine $(0.065 \mathrm{mM})$, arginine $(0.065 \mathrm{mM})$, cystine $(0.03$ $\mathrm{mM})$, and glycine $(0.03 \mathrm{mM})$ are depicted. All tissues were incubated for 45 minutes in Krebs-Ringer bicarbonate buffer, $\mathrm{pH} 7.4$, at $37^{\circ} \mathrm{C}$. The height of the bar graph represents the average distribution ratio, and the number of separate determinations is noted in parentheses. The difference between control and cystinuric subjects was significant $(p<0.001)$ for lysine, arginine, and cystine transport as determined by Student's $t$ test. The difference between control and cystinuric subjects was not significant for glycine transport. The results in patients V.H. and V.G. are discussed in the text.

\section{Results}

Total tissue water and inulin space. The total tissue water was determined to be $84.4 \pm 2.7 \%$ of wet tissue weights. $\mathrm{C}^{14}$-inulin was distributed in a volume equal to $15.5 \pm 6.1 \%$ of the wet tissue weight. There was no significant difference in either value between control and cystinuric subjects.

Characteristics of amino acid accumulation by jejunal mucosa in vitro. In segments of normal human intestinal mucosa, glycine, lysine, arginine, and cystine were accumulated against concentration gradients (distribution ratios of more than 1.0). Under conditions of anaerobiosis, the accumulation of glycine, lysine, or cystine was markedly reduced or abolished (Table I). The addition of 2,4-dinitrophenol to the incubation medium similarly depressed glycine accumulation. Thus, as expected, amino acids are accumulated in intestinal mucosa against a concentration gradient by processes that are energy dependent and require oxidative phosphorylation.

When amino acid accumulation was studied as a function of time (Figure 1), steady-state conditions were approached after 30 minutes for lysine and 45 minutes for cystine.

As the concentration of cystine or lysine in the incubation medium was increased, the rate of accumulation of these amino acids approached a maximal value, indicating that the transport 
mechanisms were behaving as saturable systems. When amino acid uptake was measured during the phase of rapid accumulation (15 minutes for lysine and 30 minutes for cystine) and the rate of uptake was plotted as a function of initial medium amino acid concentrations according to the double reciprocal method of Lineweaver and Burk (13), values for maximal transport rate $\left(\mathrm{V}_{\max }\right)$ and apparent affinity constants for transport $(\mathrm{Km})$ were ascertained. The $\mathrm{Km}$ for lysine transport calculated in this manner was 2.5 $\mathrm{mM}$ and for cystine transport $0.71 \mathrm{mM}$ (Figure 2 ), averaging data from four and three subjects respectively.

The intestinal transport defect in cystinuria. Cystine, lysine, and arginine uptake by intestinal mucosa from patients with cystinuria was markedly impaired (Figure 3 ). In ten of 12 patients with cystinuria, active transport of the three amino acids was drastically reduced or absent. Patients V.H. and V.G., although they have classical clinical cystinuria, were able to accumulate cystine in their intestinal mucosa as well as normals and were able to concentrate arginine or lysine or both better than the ten other cystinurics but not so well as normals (Table II and Figure 3). These patients will be discussed in more detail subsequently.

To evaluate the possibility that patients with cystinuria can achieve normal intracellular concentrations of the involved amino acids, but at slower than normal rates, studies were carried out in which distribution ratios for lysine and cystine were measured after $15,30,45$, and 90 minutes of incubation. The data presented in Figure 1A and $1 \mathrm{~B}$ indicate that tissue from patients with cystinuria did not concentrate cystine or lysine significantly at any of the time points studied.

TABLE II

A mino acid uptake by intestinal mucosa in control and cystinuric subjects*

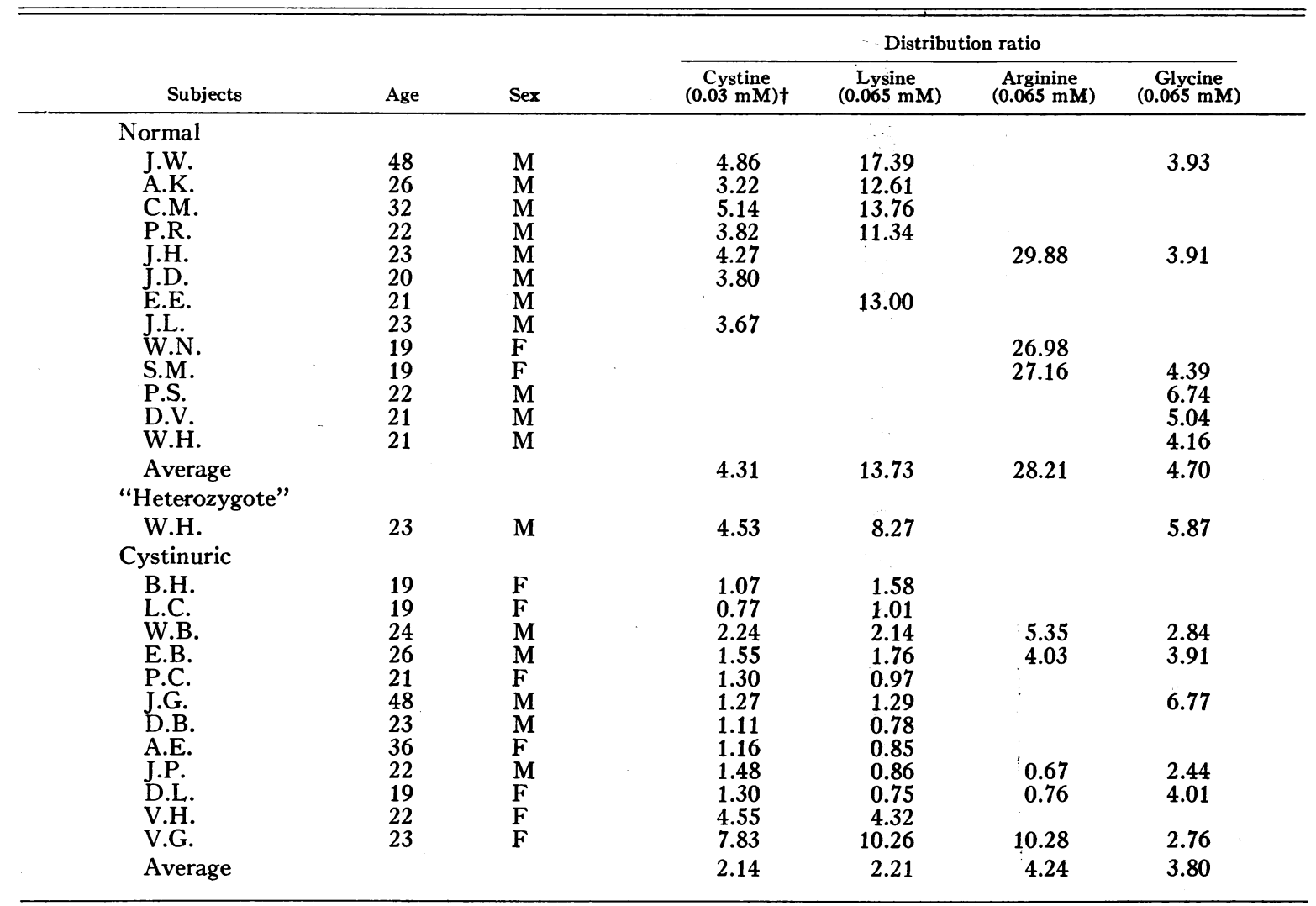

* All values were obtained from 45-minute incubation studies. V.H. and V.G. are included with the other cystinuric subjects, but their data are distinctly different (see text). "Heterozygote" W.H. is the brother of cystinuric subjects B.H. and L.C.

† Values in parentheses indicate initial medium concentration. 


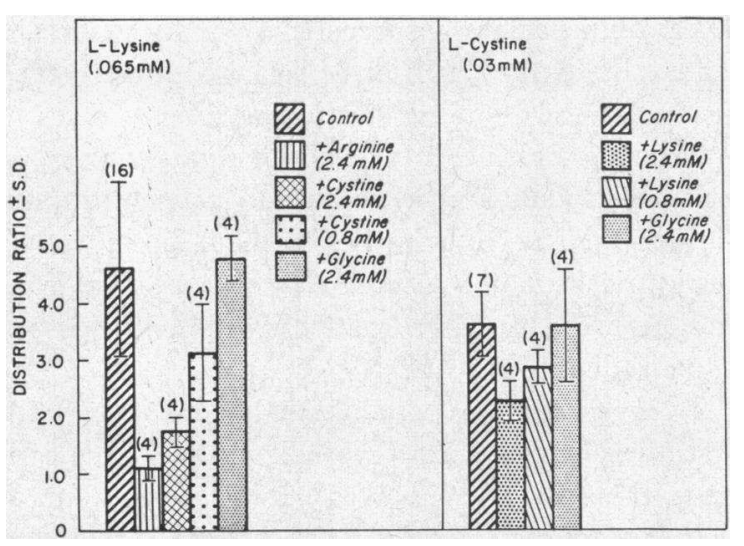

Fig. 4. EFFECT OF A SECOND AMINo ACID ON THE UPTAKE OF L-LYSINE-C ${ }^{14}$ OR L-CYSTINE-S ${ }^{35}$ BY NORMAL HUMAN INTESTINE. The duration of incubation in the studies with L-lysine as substrate was 15 minutes; 30minute incubations were used when L-cystine was the substrate. The inhibition of lysine transport by arginine and two concentrations of cystine was significant ( $p$ $<0.001,<0.001$, and $<0.02$, respectively). The inhibition of cystine by both concentrations of lysine was significant $(\mathrm{p}<0.001$ and $<0.05$, respectively). Glycine failed to inhibit transport of either amino acid.

Inhibition of cystine and lysine transport by unlabeled amino acids. Lysine accumulation in normal human intestinal mucosa was measured in the presence and absence of unlabeled arginine, cystine, and glycine, and cystine accumulation was measured in the presence and absence of unlabeled lysine and glycine. The data in Figure 4 indicate that lysine accumulation was inhibited by arginine and by both concentrations of cystine tested but not by glycine. Cystine accumulation was inhibited by both concentrations of lysine tested but not by glycine. It was not possible to obtain sufficient tissue from a single biopsy to determine whether the inhibition was competitive or noncompetitive, but the failure of glycine to inhibit the transport of either cystine or lysine suggests that the inhibition observed has some degree of specificity.

\section{Discussion}

In the present studies the findings of Spencer, Bow, Markulis, and Brody (14) demonstrating uptake of amino acids by intestinal mucosa in vitro have been confirmed and extended. It has been demonstrated that human intestinal mucosa is capable of accumulating amino acids by saturable transport mechanisms that are inhibited by anaerobiosis and uncoupling of oxidative phosphorylation. Since cystinuria was first viewed as a disease of altered sulfur metabolism (15) and later as a disease of renal tubular dysfunction (2), much of the work suggesting the presence of an intestinal transport defect was not fully appreciated. Thus the finding of putrescine and cadaverine in the urine and feces of a patient with cystinuria in 1890 (4) and the finding of impaired intestinal absorption of cystine in 1935 (5) and again in 1954 (6) were largely overlooked. The studies of Milne, Asatoor, and coworkers $(7,8)$, indicating that an intestinal transport defect exists in cystinuria, have been confirmed by in vitro studies from this laboratory and by others (9).

In the process of active transport by which a chemical concentration gradient is established between intracellular and extracellular fluid, both influx and efflux of amino acid are taking place. The failure to observe accumulation of cystine and the dibasic amino acids against a gradient in gut from cystinuric subjects may be due to a specific acceleration of efflux, but the time course of amino acid uptake (Figure 1) makes this possibility seem unlikely. These experiments demonstrate depressed intracellular concentrations of cystine and lysine in gut from cystinuric subjects at the earliest time point studied, suggesting that the rate of entry of these substances into the intracellular fluid has been markedly slowed. Such a slowing of influx would be expected if the specific carrier mechanism involved in the "uphill" transport of these amino acids were absent or defective.

The demonstration of an intestinal transport defect in cystinuria indicates that at least two tissues specifically modified for biological active transport are involved in this disease. Of potentially greater significance is the finding of a different defect in kidney and intestine in the same disorder. In human kidney cortex slices from cystinuric subjects, cystine accumulation was normal, but uptake of lysine and arginine was defective (2). Furthermore, cystine did not share a transport mechanism with lysine, arginine, and ornithine. In the gut, cystine transport, as well as lysine and arginine transport, was defective in cystinuria, and cystine and lysine were mutually 
inhibitory. These differences in renal and intestinal transport were demonstrated by comparable experimental techniques, substrate concentrations, and inhibitor concentrations. Furthermore, the differences have been observed in three cystinuric patients (B.H., L.C., and P.C.) in whom both tissues were studied.

Animal studies have suggested that there is indeed a difference in the intestinal and renal handling of cystine and the dibasic amino acids. A1though Hagihira, Lin, Samiy, and Wilson (16) showed that cystine could inhibit lysine transport in segments of hamster intestine, Rosenberg, Downing, and Segal (17), using lower substrate concentrations, failed to demonstrate similar inhibition in kidney cortex slices from rat, dog, and monkey. The observed differences in renal and intestinal uptake may reflect in vitro artifacts rather than physiologically significant alterations, but Frimpter's recent observations suggest that this is unlikely (18). He studied a single cystinuric subject and found a very high renal arteriovenous (a-v) difference for cysteine in the presence of an apparently normal a-v difference for cystine. He therefore suggested that plasma cysteine rather than cystine might be the source of urinary cystine in cystinuria. His results, coupled with the in vitro findings previously and presently reported from this laboratory, indicate that future investigations into the pathogenesis of this disorder must consider sulfhydryl-disulfide interaction between cysteine and cystine as well as transport mechanisms for cysteine in the gut and kidney.

Each of the thirteen cystinuric subjects had classical clinical cystinuria, characterized by cystine renal calculi and elevated urinary cystine, arginine, ornithine, and lysine. However, two of the 13 (V.H. and V.G.) were found to have intact intestinal transport mechanisms for cystine and only partially defective uptake of lysine and arginine. Although these results raise the possibility that cystinuria is more than one disease, they may equally well be explained on genetic grounds. The homozygous state for cystinuria may be characterized by the absence of active transport of the involved amino acids; the heterozygous state may be reflected by the partial defect seen in V.H. and V.G. The results in W.H., a brother of cystinuric twins with the complete intestinal defect, support this notion (Table II).
His intestinal mucosa concentrated cystine and lysine as did that of V.H. and V.G., but he had had no cystine renal stones, nor was his urinary cystine elevated. Although there is adequate precedent for the "half-defect" phenomenon in other biochemical studies of human genetic disease $(19,20)$, additional studies on families of patients with cystinuria are needed to determine whether uptake of amino acids by intestinal mucosa will provide a satisfactory genetic marker with which the mode of inheritance of cystinuria may be re-examined $(21,22)$.

\section{Summary}

1. Investigations of amino acid transport by jejunal mucosa in vitro indicate that amino acids are accumulated against concentration gradients by saturable systems that are energy dependent.

2. A defect in the transport of cystine and the dibasic amino acids is described in jejunal tissue from patients with cystinuria.

3. The intestinal transport defect in cystinuria appears to differ significantly from the previously reported renal defect. Cystine transport was defective in the intestine but not in the kidney, whereas dibasic amino acid transport was defective in both tissues. Furthermore, cystine and lysine were mutually inhibitory in the gut but not in the kidney.

4. Two patients with typical cystinuria had normal intestinal transport of cystine but reduced transport of arginine and lysine. A possible explanation of this phenomena on genetic grounds is presented.

\section{Acknowledgments}

The authors would like to express their gratitude to the following physicians for allowing us to study their patients: Drs. F. Bartter, M. Lotz, J. Potts, and J. Seegmiller, National Institutes of Health, Bethesda, Md.; Dr. D. Beard, Emory University, Atlanta, Ga.; Dr. G. Frimpter, Cornell University, New York, N. Y.

\section{References}

1. Thier, S., M. Fox, S. Segal, and L. Rosenberg. Cystinuria: in vitro demonstration of an intestinal transport defect. Science 1964, 143, 482.

2. Dent, C. E., and G. A. Rose. Aminoacid metabolism in cystinuria. Quart. J. Med. 1951, 20, 205.

3. Fox, M., S. Thier, L. Rosenberg, W. Kiser, and S. Segal. Evidence against a single renal transport 
defect in cystinuria. New Engl. J. Med. 1964, 270, 556.

4. Von Udranszky, L., and E. Baumann. Ueber das vorkommen von Diaminen, sogenannten Ptomaines, bei Cystinurie. Hoppe-Seylers Z. physiol. Chem. $1889,13,562$.

5. Brand, E., G. F. Cahill, and M. M. Harris. Cystinuria. IV. The metabolism of cystine, cysteine, methionine, and glutathione. J. biol. Chem. 1935, 109, 69.

6. Dent, C. E., J. G. Heathcote, and G. E. Joron. Pathogenesis of cystinuria. I. Chromatographic and microbiological studies, of the metabolism of sulfur-containing amino-acids. J. clin. Invest. 1954, $33,1210$.

7. Milne, M. D., A. M. Asatoor, K. D. G. Edwards, and L. W. Loughridge. The intestinal absorption defect in cystinuria. Gut 1961, 2, 323.

8. Asatoor, A. M., B. W. Lacey, D. R. London, and M. D. Milne. Amino acid metabolism in cystinuria. Clin. Sci. 1962, 23, 285.

9. McCarthy, C. F., J. L. Borland, Jr., H. J. Lynch, Jr., E. E. Owen, and M. P. Tyor. Defective uptake of basic amino acids and L-cystine by intestinal mucosa of patients with cystinuria. J. clin. Invest. 1964, 43, 1518.

10. Wilbrandt, W., and T. Rosenberg. The concept of carrier transport and its corollaries in pharmacology. Pharmacol. Rev. 1961, 13, 109.

11. Akedo, H., and H. N. Christensen. Nature of insulin action on amino acid uptake by the isolated diaphragm. J. biol. Chem. 1962, 237, 118.

12. Krane, S. M., and R. K. Crane. The accumulation of $\mathrm{D}$-galactose against a concentration gradient by slices of rabbit kidney cortex. J. biol. Chem. 1959, 234, 211.

13. Lineweaver, H., and D. Burk. The determination of enzyme dissociation constants. J. Amer. chem. Soc. 1934, 56, 658.

14. Spencer, R. P., T. M. Bow, M. A. Markulis, and K. R. Brody. Enzymatic assay and glucose and amino acid uptake of intestinal biopsy specimens. Amer. J. dig. Dis. 1963, 8, 419.

15. Garrod, A. E. The Croonian lectures on inborn errors of metabolism. Lancet 1908, 2, 142, 214.

16. Hagihira, H., E. C. C. Lin, A. H. Samiy, and T. H. Wilson. Active transport of lysine, ornithine, arginine, and cystine by the intestine. Biochem. biophys. Res. Commun. 1961, 4, 478.

17. Rosenberg, L. E., S. J. Downing, and S. Segal. Competitive inhibition of dibasic amino acid transport in rat kidney. J. biol. Chem. 1962, 237, 2265.

18. Frimpter, G. W. Cystinuria: metabolism of the disulfide of cysteine and homocysteine. J. clin. Invest. 1963, 42, 1956.

19. Kirkman, H. N., and E. Bynum. Enzymatic evidence of a galactosemic trait in parents and galactosemic children. Ann. hum. Genet. 1959, 23, 117.

20. Williams, H. E., and J. B. Field. Low leukocyte phosphorylase in hepatic phosphorylase-deficient glycogen storage disease. J. clin. Invest. 1961, 40, 1841.

21. Harris, H., U. Mittwoch, E. B. Robson, and F. L. Warren. The pattern of amino-acid excretion in cystinuria. Ann. hum. Genet. 1955, 19, 196.

22. Harris, H., U. Mittwoch, E. B. Robson, and F. L. Warren. Phenotypes and genotypes in cystinuria. Ann. hum. Genet. 1955, 20, 57. 